\title{
ВЫРАЖЕНИЕ ЯЗЫКОВЫХ СРЕДСТВ КОНТАКТА В РУССКИХ И КИТАЙСКИХ ПУБЛИЧНЫХ ВЫСТУПЛЕНИЯХ
}

\section{EXPRESSION OF LINGUISTIC MEANS OF CONTACT IN RUSSIAN AND CHINESE PUBLIC SPEECHES}

\section{Kong Haiping}

Summary: This article describes the linguistic means of contact in Russian and Chinese public speeches and their roles in speeches. The study is based on the the speech of the President of Russia at the military parade and the speech of the President of China at the global summit on health issues. The author briefly describes the current state of rhetoric research in Russia and China, compares the differences and connections between rhetoric, eloquence and stylistics in terms of definitions, research objects, names in Chinese, etc. In this article, the author mainly analyzes the expression of linguistic means of contact in Russian and Chinese public speeches, and also discusses the roles of these means in speeches.

Keywords: rhetoric, stylistics, linguistic means of contact, public speeches.
Аспирант, Пекинский университет иностранных языков,

2. Пекин, КНР

konghaipingkhp@126.com

Аннотация: Статья посвящена исследованию языковых средств контакта в русских и китайских публичных выступлениях и их роли в речах. Материалом послужили выступление Президента России на военном параде и выступление Председателя Китая на глобальном саммите по вопросам здравоохранения. Автор кратко описывает текущее состояние исследования риторики в России и Китае, сравнивает различия и связи между риторикой, красноречием и стилистикой с точки зрения определения, объекта исследования, названия на китайском языке и т.д. В статье в основном анализируется выражение языковых средств контакта в русских и китайских публичных выступлениях, а также рассматриваются роли данных средств в речах.

Ключевые слова: риторика, стилистика, языковые средства контакта, публичные выступления.

\section{Введение}

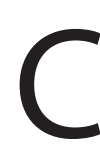

лово «риторика» происходит от греческого Rhetorike. Самая ранняя из дошедших до нас отечественных риторик относится к началу XVII В. [Кохтев 1994: 24]. Риторика как дисциплина пережила в России более 300 лет развития: период становления в начале XVII - начале XVIII веков, период развития XVIII и XIX веков, период упадка середины XIX века и середины XX века и этап полномасштабного возрождения после 1970-1980-х гг.. В настоящее время теоретические и практические исследования риторики демонстрируют тенденцию устойчивого развития. А в Китае риторика имеет свои особенности развития. Китайские учёные уделяют пристальное внимание тенденции развития русской риторики, уделяя особое внимание следующим аспектам: понимание русской терминологии, объяснение коннотации риторики; введение в основные теории или концепции классической риторики, например, «Понимание и применение основных идей риторики» Ван Цзяфэя (1998); обсуждение сходства и различий между риторикой и стилистикой, таких как «Риторика и стилистика» Чжан Хуэйцинь (2000), «Повторное обсуждение о риторике и стилистике» Фань Минмина (2006) и др .; Исследования в области риторики, например, монография Чжан Хуэйцинь «Речевое мастерство педагога» (2008г.), в которой объясняется основное содержание педагогической риторики; макроисследование современной риторики, такое как монография «Риторика» (2007 г.). Из- учение риторики в Китае находится в зачаточном состоянии, и необходимо усилить введение и исследование этого предмета [Линь Мэй 2010: 10].

В последние годы, с постоянным развитием риторики, применение ее языковых средств контакта в публичных выступлениях становится все более очевидным, а их интеграция с публичными выступлениями становится все более и более тесной. Прежде чем приступить к анализу языковых средств контакта в публичных выступлениях, в нашей работе рассматриваются два вопроса: 1. Различить два понятия, которые легко спутать с риторикой, 2. Уточнить связь между риторикой и публичными выступлениями. Объяснение этих двух вопросов способствует дальнейшему анализу.

\section{1. Различие и связь межАу риторикой и поАобными концепциями}

С самого начала риторику путали с другими понятиями: красноречие, стилистика. Ученые проделали большую работу по интерпретации и дифференциации этих понятий. Чтобы лучше понять содержание риторики, необходимо различить эти понятия и уточнить отношения между ними.

\section{1 Риторика и красноречие}

Прежде всего, два термина происходят из разных 
источников: риторика - заимствованное слово, а красноречие - исконно русское слово. Во-вторых, два понятия имеют разные значения. Значение слова риторика сильно варьируется в разные исторические периоды. Аристотель определил её как «искусство убеждать», Цицерон считал её «искусством трогать, обучать и развлекать слушателей», Квинтилиан считал, что она «искусство говорить хорошо», а в средневековье и в эпоху Возрождения риторика считалась «искусством украшения речи». В целом риторика - это наука о мышлении и выражении. О убеждении по мнению греческих теоретиков это обозначает воздействие на аудиторию посредством выступлений, чтобы аудитория могла принять определенные мнения. Аристотель считает, что риторика выполняет «функцию поиска возможных способов убеждения по любому вопросу» [Ван Цзяфэй 1998: 13]. Из приведенного выше обсуждения видно, что на самом деле риторика изучает конкретную публичную речь, то есть ораторскую речь. Красноречие имеет два значения: способность, умение излагать мысли красиво и убедительно; изучение ораторского искусства. В втором смысле красноречие близко к риторике [Фань Минмин 2001: 16].

\section{2 Риторика и стилистика}

Различие и связь между этими двумя концепциями тема, которую часто обсуждают китайские ученые. Причина в том, что отношения между ними очень сложны, что заставляет ученых понимать их по-разному.

\subsection{1 Различные научные определения}

Риторика - это «предмет, сочетающий теорию и практику ... это предмет об эффективности речевого общения, и предмет, в котором слова используются для достижения коммуникативного эффекта и оптимизации коммуникативных результатов» [Фань Минмин 2007: 100]. Стилистика - это чисто лингвистический предмет, «предмет исследования стилистики являются выразительные возможности и средства разных уровней языковой системы, их стилистические значения и окраски, а также закономерности употребления языка в разных сферах и ситуациях общения...» [Кожина, Дускаева, Салимовский 2011: 28]. Китайские ученые также придерживаются того же мнения, что стилистика - это «чисто лингвистический предмет, изучающий определенные лингвистические вопросы на речевом уровне» [Фань Минмин 2007: 100]. Видно, что дисциплинарное позиционирование двух концепций разное. Риторика - это не только языковой предмет, но и всеобъемлющий предмет, сфокусированный на всем процессе от мысли до языка, который является всеобъемлющим и целостным. Российский лингвист по риторике В. И. Аннушкин отметил, что риторика - теория и практика речи развитого информативного общества, предполагающая изучение большого разнообра- зия текстов, включенных в культуру [Аннушкин 2016: 44]. Риторика - это также искусство «мыслить». Обучение речи невозможно без одновременного обучения мыслить, формировать мировоззрение, получать знания и выражать свою жизненную позицию в слове [Аннушкин 2016: 43]. А что касается стилистики, как мы знаем, она лингвистическая наука, разработанная на основе современной лингвистики Соссюра и основанная на лингвистических теориях. Предпосылка изучения стилистики - овладение знаниями лексики, грамматики и другие в лингвистике.

\subsection{2 Различные объекты исследования}

Риторика фокусируется «не столько на вопросе чистой структуры речи, сколько на вопросе использования красивой и разумной речи для достижения желаемых результатов» [Фань Минмин 2006: 25]. Возьмем, к примеру, частную риторику. С непрерывным развитием риторики, её область расширилась. Среди них особое внимание привлекла современная частная риторика, которая «касается всех видов речевого взаимодействия: от обыденной риторики до политической, педагогической, юридической и многих других видов частной риторики» [Аннушкин 2016: 41]. Существенной характеристикой стилистики является изучение динамического языка, изучение законов функции языка в различных социальных действиях и ситуациях общения, а также изучение выразительных средств языка. Её объект исследования стиль. Другими словами, стилистика обращает внимание на разновидности речи.

\subsection{3 Различные названия на китайском языке}

Существует несколько разных названий для китайского перевода риторики - 古典修辞学(классическая риторика)，西方古典修辞学(западная классическая риторика), 演讲术(наука о выступлении), 雄辩术(ораторское искусство) и т. д., но эти названия не совсем отражают гуманитарную мысль риторики. Китайский учёный в области английского языка Гу Юего считает, что Rhetoric представляет гуманистическую традицию, a Stylistics представляет стилистическую традицию. Мы переводим Stylistics как 《语体文体修辞学》 и Rhetoric как “人文修辞学》 [Гу Юего 1990: 15-16]. Такие переводы получили признание и одобрение китайских ученых в области русского языка. Фань Минмин также считает, что китайский перевод стилистики - это «语体文体修 辞学》, а китайское название риторики - «人文修辞学》. Нам кажется, что китайское название риторики «人文 修辞学》 отражает её гуманитарную мысль. Поскольку риторика - это «риторика для целей межличностного общения» [Цун Лайтин 2007: 355]. Она рассматривает риторическую деятельность как социальные атрибуты и социальную деятельность людей, и имеет очевидные гуманистические атрибуты. 


\subsection{4 Связь межАу риторикой и стилистикой}

Истоки стилистики восходят к риторике в Древней Греции. Риторика включает в себя факторы стилистики. После упадка риторики стилистика унаследовала часть ее содержания, но это не простое наследство, а превратилась в современную языковую науку с новым содержанием на основе новой теории [Чжан Хуэйцинь 2000: 47-48]. Другими словами, стилистика превратилась в современный языковой предмет из риторики. Если мы посмотрим на классическую стилистику с точки зрения дихотомии, то риторика и стилистика - две относительные её классификации, но фокус их исследования разный. Риторика - это «наука в общем смысле, кроме стилистического стиля в западной классической стилистике» [Цун Лайтин 2007: 355]. Наукой, которая обращает внимание на стили, речевые варианты и т.д., является стилистика. Для риторики стилистика - это всего лишь средство для достижения цели общения и получения эффективных результатов в широком смысле [Фань Минмин 2007: 100].

\section{2. Связь межАу риторикой и публичными выступлениями}

Основная идея риторики - это «убеждение» [Ван Цзяфэй 1998: 16]. Для этого нужно опираться на логос (logos), то есть внутреннюю логику и языковые навыки самой речи; нужно опираться на этос (ethos), то есть моральный облик, авторитет и престиж оратора; нужно опираться на пафос (pathos), то есть состояние и отношение аудитории, понимание психологии аудитории и обращение к их эмоциям. Это совпадает с целью выступления. Выступление также называется «речь», является высшей формой устного выражения, которая тесно сочетает в себе «выступление» и «речь». Это социальная деятельность, нацеленная на широкую аудиторию и выражающая субъективные мысли и чувства с целью убеждения, заражения, обучения и изменения мыслей и поведения людей [Цзи Шичан, Чжу Цзинчжи 1988: 2]. Видно, что целью выступления тоже является убеждение. Речь выступления должна быть логичной и образной, что соответствует логосу риторики; сам говорящий обладает благородными моральными качествами, что соответствует этосу риторики. «Выступление - это результат взаимодействия между говорящим, темой и аудиторией в конкретном случае» [Кеннет Берк 1998: 8-9]. Для выступления также требует множественных взаимодействий и сотрудничества между говорящим и аудиторией, что соответствует пафосу риторики. Кроме того, необходимы другие факторы, такие как тон говорящего, мимики и жесты. В общем, успешное выступление - это результат взаимодействия множества факторов.

Аристотель подчеркивал ключевую роль характера говорящего и эмоционального состояния аудитории в выступлении, что говорящий может в полной мере ис- пользовать психологию аудитории для достижения убеждения. Оратор должен сначала привлечь аудиторию своим личным обаянием, чтобы у аудитории было чувство доверия, а затем в процессе выступления он должен выбирать различные способы убеждения в соответствии с различными психологическими состояниями аудитории, чтобы повысить убедительность речи. «Потому что, когда люди проявляют дружелюбие или ненависть, гневное или нежное отношение, у них разные взгляды на дела» [Аристотель 1991: 69-70]. С 1980-х годов риторика была полностью возрождена и развита. Мотивация для ее развития заключается в том, что «этот предмет в наибольшей степени удовлетворяет риторические потребности общества и стал доктриной, имеющей большое руководящее значение в практике использования речи людьми» [Линь Мэй 2010: 10]. Сочетание риторики и речевой практики становится все ближе и ближе, а руководящая роль риторики для выступления становится все более очевидной. Например, языковые средства контакта включают средства авторизации с точки зрения оратора и средства адресации с точки зрения аудитории. Эти средства учитывают как говорящего, так и аудиторию, а их функция и цель - убеждение. Использование языковых средств контакта риторики в выступлениях может сократить расстояние между оратором и аудиторией и лучше достичь цели. Это особенно очевидно в политических публичных выступлениях с сильной пропагандой. Мы берем выступление на военном параде в День Победы Президента РФ В.В. Путина 9-ого мая 2021г. и выступление на глобальном саммите по вопросам здравоохранения Председателя КНР Си Цзиньпина 21-ого мая 2021 г. в качестве материала, чтобы проанализировать языковые средства контакта в выступлениях, понять роль риторики в речи, углубить понимание риторики и понять позицию и отношение ораторов.

\section{3. Выражение языковых средств контакта в публичных выступлениях}

Российский лингвист Н.Н. Кохтев разделяет языковые средства контакта на два типа: средства авторизации и средства адресации. Можно определить авторизацию как способ проявления «я» оратора при помощи разнообразных языковых средств, которые придают сообщению субъективный характер и способствует установлению коммуникативного контакта между оратором и слушателями [Кохтев 2012: 198]. Языковые средства авторизации включают в себя личные местоимения «я» и «мы», глагольные формы множественного числа первого лица, конструкции с вводными элементами мне кажется..., конструкции с изъяснительными придаточными (ясно, что...) и другие. К наиболее распространенным языковым средствам адресации относятся: обращения, местоимения и глагольные формы второго лица множественного числа, императив и побудительные конструкции, экспрессивные контактоустанавливающие сред- 
ства. Ниже мы будем проанализировать вышесказанные языковые средства контакта в публичных выступлениях и посмотрим, как оратор передает сообщение и своё личное отношение к сообщению.

\section{1. Языковые средства авторизаши}

\subsection{1 ^ичные местоимения «я» и «мы» в нужннй форме}

В выступлениях Путина нет местоимения «я» и его косвенных падежей, там только опустили слово «я» в предложении «Поздравляю вас с Днём Победы!». В речи существуют многие «мы» и их косвенных падежи. Мы и его косвенные падежи означают оратора, слушателей и даже всех людей, связанных с Днём Победы. Употребление местоимения мы и его косвенных падежей помогает создать и передать атмосферу взаимопонимания между Путиным и слушателями. Посмотрим следующие примеры:

Наши ветераны, их судьбы, их преданность Родине - это пример для нас. Вершина, к которой мы должны стремиться и утверждать значимость, ченность грандиозной Победы в наших помыслах и поступках, в наших делах и будущих свершениях во имя Отечества.

В выступлениях Си Цзиньпина ораторское «я» эксплицитно выражено разными способами: 我(я) или我们 (мы). Здесь я не только представляет оратора, но и представляет китайское правительство. Употребление местоимения я показывает решительность, советы, меры и вклады Китая в борьбе с COVID-19 и помогает создать хороший национальный имидж Китая в глобальном сотрудничестве. Ниже примеры:

第四，坚持公平合理，弥合“免疫鸿沟”。我在一年前 提出，疫苗应该成为全球公共产品。( В-четвертых， 8 справедливом и рачиональном ключе устранять «иммунную яму». Как я предложил в прошлом году, вакцина должна стать глобальным общественным благом.)

Употребление местоимения мы помогает сократить психологическую дистанцию с аудиторией. «Мы» выражает важность совместного сотрудничества в сдерживании заболевания. Например:

古罗马哲人塞涅卡说过，我们是同一片大海的海浪。

(Древнеримский философ Сенека сказал: «Мы волны одного и того же моря».)

\subsection{2 Глагольные формы первого ^иша множественного числа}

В выступлениях Путина и Си Цзиньпина немало глагольных форм, функционирование которых соответствует местоимению мы. С одной стороны, глаголы передают движение; с другой стороны, они выражают отношение к лицу и, таким образом, являются указателями субъективности в высказывании [Кохтев 2012: 201]. Иногда гла- гольные формы первого лица множественного числа не используются одинаково, а вместе с местоимением мы, тогда они обладают категорией лица. Такие конструкции объединяют оратора и слушателей в совместном действии, мыслительном или физическом. Здесь конструкции с глагольными формами получают контактоустанавливающее значение. Например, глагольные формы склоняем, скорбим, отдаём и вспоминаем объединяют оратора и слушателей в единое целое и выражают уважение к героям, любовь к Родине, решительность защищать национальные интересы и т.д.. А в речи Си Цзиньпина глаголы долженствования要 с местоимением我们 образуют подлежащее и сказуемое我们要( в высказывании и показывают концепцию сотрудничества Китая и будущие мероприятия Китая и других стран в борьбе с эпидемией.

Мы склоняем головы перед светлой памятью всех, чью жизнь отняла́ война́: перед памятью сыновей, дочерей, отиов, матерей, дедов, мужей, жён, братьев, сестёр, однополчан, родных, друзей. Скорбим о ветеранах, которые ушли от нас.

Сегодня мы отдаём дань памяти и благодарности всему поколению великих героев и тружеников, вспоминаем фронтовиков, храбрых партизан и подпольщиков.

面对传染病大流行，我们要秉持人类卫生健康共同体 理念，团结合作、共克时艰，坚决反对各种政治化、标 签化、污名化的企图。(Перед лицом пандемии мы должны претворять в жизнь концепиию сообщества единого здравоохранения человечества, объединять усилия для достижения победы над вспышкой, решительно противостоять разного рода попыткам политизации, стигматизации и дискредитации.)

Видим, что глаголы первого лица множественного числа обладают значением совместного действия. Более того, некоторые глаголы имеют значение побуждения, как будем защищать, 我们要秉持 $($ мы должны претворять). Оратор как бы привлекает слушателей к участию в обсуждении фактов, мыслей [Кохтев 2012: 202].

\subsection{3 Конструкшии с вводными элементами}

В публичных выступлениях цель заключается не только в передаче сообщения о действительности, но в выражении отношения к ней оратора. Конструкции с вводными элементами могут выражать ораторское «я», поэтому являются одним из средств авторизации. В речи Путина существуют несколько конструкций с вводными элементами, такие как казалось бы, а значит, к сожалению, и конечно и т.д., и они выражают разные эмоции оратора к сообщаемому.

Вы доказали, что только вместе можно достичь, ка- 
залось бы, невозможного.

Здесь казалось бы означает, что великие солдаты смогут достичь невозможных задач, хотя эти задачи были тяжёлыми.

Но тогда, в 1941-м, впереди было ешё четыре года самой кровопролитной войны. Она била по будущему, по молодым, совсем юным поколениям, а значит, и по тем, кому так и не суждено было родиться.

Вводный элемент значит подчёркивает негативные и жестокие последствия войны для людей. Здесь чётко выражается отношение оратора к войне.

История требует делать выводы и извлекать уроки. Но, к сожалению, многое из идеологии нацистов, тех, кто был одержим бредовой теорией о своей исключительности, вновь пытаются поставить на вооружение.

Вводные элементы к сожалению обращают внимание слушателей на идеологии нацистов и выражают отрицательное отношение оратора к ним.

Надёжные гарантии тому - доблестные Вооружённые Силы России, наследники солдат Победы. И конечно, наша совместная работа ради развития страны, ради благополучия российских семей.

В этом примере вводные элементы и конечно не только связывает предыдущее предложение, но и подчеркивает вклад армии в защиту страны и народа. В то же время мы можем чувствовать национальную гордость оратора.

\subsection{4 Конструкшии с изъяснительными приАаточными}

К языковым средствам авторизации относятся конструкции с изъяснительными придаточными. По мнению И.И. Формановской, изъясняемые слова разделяют на три типа: констатирующие, субъектно-модальные, оценочные. К констатирующим относятся те, которые лишь устанавливают факт сообщения, мысли, восприятия без добавочных оттенков (известно, что...). К субъективно-модальным относятся те слова, которые содержат добавочные оттенки - уверенности, не уверенности, предположительности и т.д. (уверен, что...). Оценочные слова в главной части - это чаще всего безлично-предикативные слова (ясно, понятно...) и краткие прилагательные, а также глаголы [Формановская 1978: 60]. В выбранных выступлениях мы только нашли обычные изъяснительные предложения, то есть, констатирующие конструкции, а не нашли оценочно-изъяснительные и модально-изъяснительные конструкции. Констатирующие изъяснительные конструкции объективно переда- ют какие-то факты сообщения или восприятия. Например, помнить что, показать что.

Мы всегда будем помнить, что этот величественный подвиг совершил именно советский народ.

实践证明，要彻底战胜疫情，必须把人民生命安全 和身体健康放在突出位置...... (Практика показала， 4mo для окончательной победы необходимо уделять первоочередное внимание безопасности и здоровью людей...)

\section{2. Языковые срехства ацресации}

\subsection{1 Конструкшии с обрашением}

Обращения - это название реальных или предполагаемых лиц. В речах используются обращения «с целью привлечь внимание тех, к кому направлена речь, вызвать у них определённую реакцию на сообщение» [Кохтев 2012: 206]. Можно разделять обращения на нейтрально-официальные обращения, ситуативные формы обращения, обращения к друзьям, коллегам и другие. В наших примерах обнаруживаются некоторые типы обращений: официальные обращения, обращения к друзьям и коллегам. Они в выступлениях выполняют функцию активизации внимания аудитории. Посмотрим на следующие обращения:

Официальные обращения:

Уважаемые граждане России!

Товарищи солдаты и матросы, сержанты и старшины, мичманы и прапорщики! Товарищи офицеры, генералы и адмиралы!

尊敬的德拉吉总理! (Уважаемый премьер-министр Марио Драги!)

Обращения к друзьям или к коллегам:

Дорогие друзья!

各位同事(Коллеги!)

Употребление обращений в речах помогает не только создать контакты между оратором и аудиторией, но и обратить внимание слушателей на излагаемый материал, чтобы они лучше поняли содержание речи.

Н.Н. Кохтев считает, что вводные конструкции, содержащие адресованность, типа как вы понимаете, как вы догадываетесь, как видите, как вы знаете, как мы знаем по своей функции в речи приближаются к собственно обращениям за счет ослабления их информативного плана [Кохтев 2012: 206]. Они также являются языковыми средствами адресации, так как «эти вводные конструкции апеллируют к знаниям, памяти слушателей» [Кохтев 2012: 206]. В наших материалах не обнаруживается использование таких конструкций, и мы не будем делать анализ. 


\subsection{2 Конструкшии с местоимениями и глагольными формами второго ^иша множественного числа}

Местоимение и глаголы второго лица множественного числа вы делаете (сделали) что... содержат явную адресованность, и так конструкции с ними являются языковыми средствами адресации. Местоимение вы имеет значение собеседника ты с оттенком вежливости, слушателей или других. Обычно оратор использует местоимение вы в значении «вы - слушатели» или «вы - слушатели и другие». В примере «Вы доказали, что только вместе можно достичь, казалось бы, невозможного. Одолели беспощадного врага, защитили свой дом, детей, родную страну. Одержали над нацизмом безоговорочную Победу и прославили в веках 9 мая 1945 года.» местоимение вы используется в значении «вы - ветераны». С помощью местоимения и глаголов вы доказали, одолели, защищали, одержали оратор привлекает внимание слушателей-ветеранов и подчеркивает их подвиги в Великой Отечественной войне, и в то же время вызывает уважение аудитории к военным. Иногда местоимение второго лица используется вместе с местоимением первого лица: «Поздравляю вас с Днём Победы!»

\subsection{3 Побудительные конструкшии}

Побудительные конструкции обладают ориентированностью на контактность речи и относятся к особым средствам адресации. Оратор употребляет побудительные конструкции в речи для побуждения аудитории к каким-нибудь действиям. Наиболее распространенные императивы - это конструкции с глагольными формами второго лица, как делайте, подумайте и т.д. В нашем примере используется побудительная конструкция с давайте с целью побудить слушателей к совместным действиям - глобальному противоэпидемическому сотрудничеству. Побудительное слово 让我们(Давайте) выражает «непосредственное обращение оратора к слушателям с указанием выполнить то или иное действие» [Кохтев 2012: 206].

让我们携手并肩，坚定不移推进抗疫国际合作，共 同推动构建人类卫生健康共同体，共同守护人类健康美 好末来! (Давайте со всей решимостью идти рука об руку в борьбе с коронавирусом, продвигать глобальное противоэпидемическое сотрудничество во имя сообщества единого здравоохранения и прекрасного будущего человечества.)

\subsection{4 Экспрессивные контактоустанавливаюшие средства}

Н.Н. Кохтев считает, что риторический вопрос и вопросо-ответные единства могут вызвать реакцию аудитории. Мы не наблюдаем таких средств в нашем материале, но обнаруживаем другие контактоустанавливающие средства, такие как слова совместная работа, 共同体 (сообщество)，共商共建共享 (принципа «совместного обсуждения, совместной реализации и совместного пользования») являются активными средствами экспрессивной лексики, так как они передают экспрессивно окрашенную положительную информацию.

И конечно, наша совместная работа ради развития страны, ради благополучия российских семей.

携手共建人类卫生健康共同体 (Тема: Общими усилиями формировать сообщество единого здравоохранения человечества)

要坚持共商共建共享..... (При этом очень важно придерживаться принципа "совместного обсуждения, совместной реализации и совместного пользования»...)

\section{Зак^ючение}

Мы проанализировали языковые средства контакта в выступлениях Путина и Си Цзиньпина и обнаружили, что их речи красивы и убедительны. Использование языковых средств контакта в речах в сочетании с определенной интонацией, мимикой и телодвижениями помогает построить мост общения между оратором и аудиторией и добиться хорошего коммуникативного эффекта. Риторика является инструментом речевой коммуникации, теория которой стала всеобъемлющим и разнообразным предметом, и она присутствует во всем дискурсе. Риторика способствует правильному использованию языка, разумному общению людей и украшению гуманистической атмосферы общества. Ведь «цель риторики - совершенствовать через стиль речи стиль жизнь. Стиль жизни формируется стилем речи» [Аннушкин 2016: 37].

\section{ЛИТЕРАТУРА}

1. Аннушкин В.И. Риторика. Вводный курс. М.: Изд-во Флинта, 2016. 37-44с.

2. Кожина М.Н., Дускаева Л.Р., Салимовский В.А. Стилистика русского языка. 4-е издание. М.: Изд-во Флинта, Наука, 2011. 28 с.

3. Кохтев. Н.Н. Риторика. М.: Просвещение, 1994. 24с.

4. Кохтев. Н.Н. Основы ораторской речи. М.: Изд-во Флинта, Наука, 2012. 198-206с.

5. Формановская. Н.И. Стилистика сложного предложения. М.: Рус.яз., 1978.60с.

6. 从莱庭. 西方修辞学. 上海: 上海外语教育出版社. 2007, 355页. (Цун Лайтин. Западная стилистика. Шанхай: Шанхайская пресса по обучению ино- 
(транным языкам, 2007. 355с.)

7. 樊明明. 俄罗斯 РИТОРИКА 的发展历史与现状. 解放军外国语学报. 2001, 1: 16-20. (Фань Минмин. История развития и современное положение риторики в России // Journal of PLA University of Foreign Languages. 2001. № 1. С. 16-20.)

8. 樊明明. 再论 риторика 与 стилистика. 中国俄语教学. 2006, 2: 22-25. (Фань Минмин. Дальнейшее исследование риторики и стилистики // Russian in (hina. 2006. № 2. C. 22-25.)

9. 樊明明等. 人文修辞学. 上海: 上海外语教育出版社. 2007, 100页. (Фань Минмин и др. Риторика. Шанхай: Шанхайская пресса по обучению иностранным языкам, 2007. 100с.)

10. 顾曰国. 西方古典修辞学和西方新修辞学. 外语教学与研究. 1990, 2: 13-25. (Гу Юего. Западная классическая стилистика и новая стилистика // Foreign Language Teaching and Research. 1990. № 2. C. 13-25.)

11. 季世昌, 朱净之. 演讲学. 南京: 江苏教育出版社. 1986, 2页. (Цзи Шичан, Чжу Цзинчжи. Ораторское искусство. Нанкин: Издательство просвещения Цзянсу, 1986. 2с.)

12. [美]肯尼斯・博克(Kenneth Burke)著, 常昌富, 顾宝桐译. 当代西方修辞学: 演讲与话语批评. 北京: 中国社会科学出版社. 1998, 8-9页. (Кеннет Берк(автор), Чан Чанфу, Гу Баотун(переводы). Современная западная стилистика: речь и дискурсивная критика. Пекин: Пресса по социальным наукам Китая, 1998. 8-9с.)

13. 林梅. 俄罗斯现代人文修辞学在中国的研究. 西安外国语大学学报. 2010, 4: 8-11. (Линь Мэй. Исследование современной гуманистической риторики в Китае // Journal of Xi'an International Studies University. 2010. № 4. C. 8-11.)

14. 汪嘉斐. РИТОРИКА 基本思想的理解与应用. 外语学刊. 1998, 3: 13-21. (Ван Цзяфэй. Понимание и применение основных идей риторики // Foreign Language Research. 1998. № 3. C. 13-21.)

15. 亚里士多德著, 罗念生译. 修辞学. 北京: 三联书店. 1991, 69-70页. (Аристотель(автор), Ло Няньшэн(перевод). Стилистика. Пекин: Книжный магазин (аньлянь, 1991. 69-70с.)

16. 张惠芹. Риторика 与стилистика. 中国俄语教学. 2000, 1: 46-49. (Чжан Хуэйцинь. Риторика и стилистика // Russian in China. 2000. № 1. C. 46-49.)

() Кун Хайпин (konghaipingkhp@126.com).

Журнал «Современная наука: актуальные проблемы теории и практики»

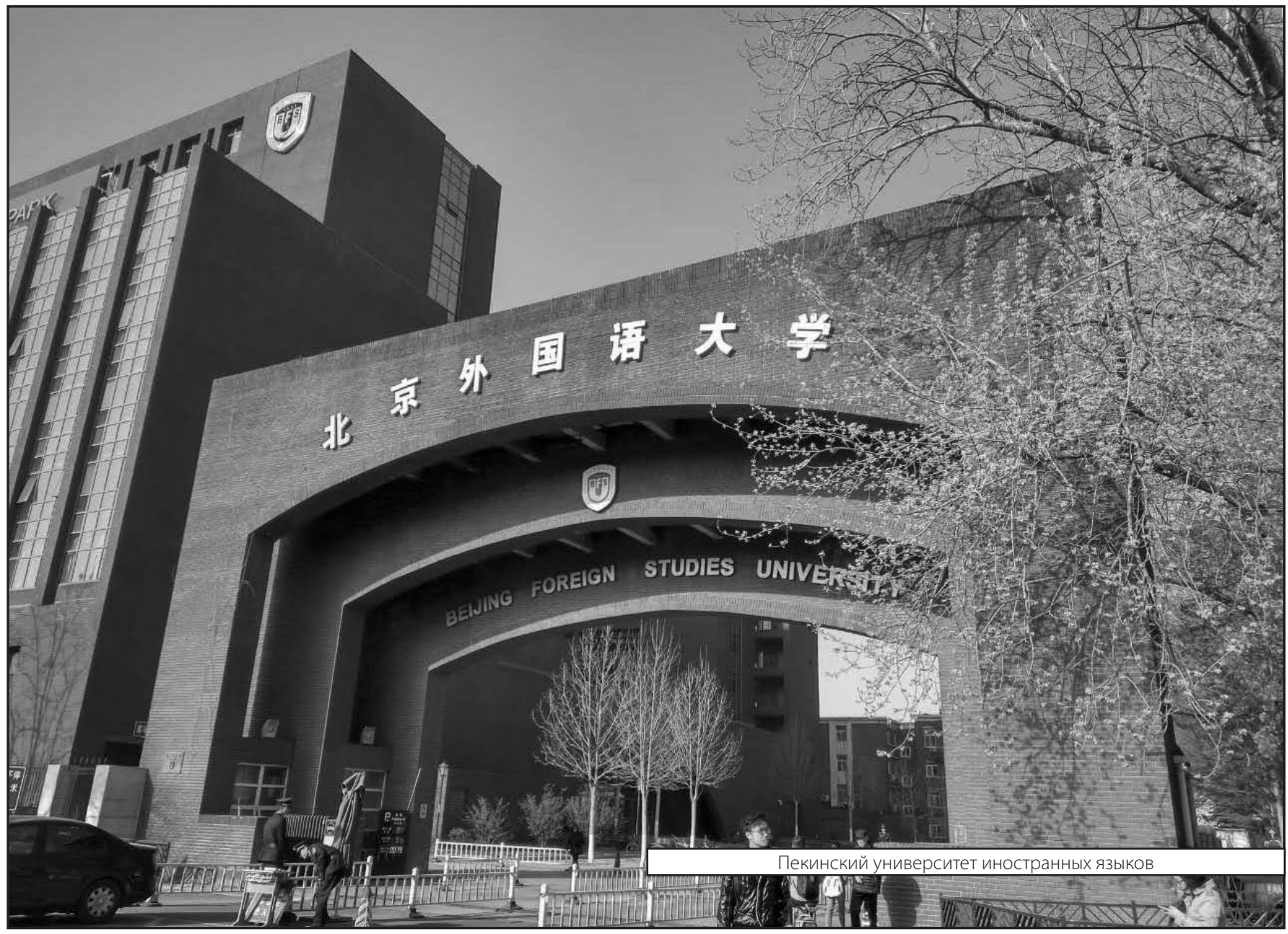

